\title{
Georges Cuvier e a instauração da Paleontologia como ciência
}

\author{
Frederico Felipe de Almeida Faria \\ ffelipe.faria@pq.cnpq.br \\ Tese de Doutorado \\ Programa de Pós-Graduação Interdisciplinar em Ciências Humanas \\ Universidade Federal de Santa Catarina \\ Florianópolis (SC) 2010
}

\begin{abstract}
Até a Modernidade, quando os fósseis começaram a ser interpretados como restos de organismos, estes fenômenos naturais receberiam inúmeras interpretações que os relacionaria à mitologias e magismo. Mesmo após o reconhecimento de sua origem orgânica, os historiadores naturais praticamente não os ut lizavam para a produção de conhecimento. Somente quando a questão da ocorrência de extinções no mundo natural veio a ser debatida vigorosamente, o papel dos fósseis como fornecedores de dados para a compreensão deste e de outros fenômenos naturais pôde ser percebido. Mas, para a comprovação do desaparecimento de toda uma espécie, era necessária a aplicação de métodos da Anatomia Comparada. Georges Cuvier (1769-1832), ao formular estes métodos anátomocomparativos, que possib litaram as reconstruções paleontológicas, promoveu a definitiva inclusão dos fósseis no mundo biológico e na história do Globo. Esta inclusão forneceria um grande aporte de conhecimento das possíveis formas de organização corporal, que era um dos mais importantes objetivos cognitivos do programa de pesquisas de Cuvier. Para produzir este aporte, ele formou uma rede de cooperação internacional que se transformou numa comunidade cientíica, com a divulgação e aceitação dos resultados de seus trabalhos. A partir de então, esta comunidade ut lizaria os métodos de Cuvier na produção de estudos que implicavam confirmações daqueles resultados. Após décadas desta prática de ciência normal kuhniana, alguns naturalistas iriam descobrir fenômenos naturais que a teoria constituinte do paradigma cuvieriano não poderia explicar. Seguiu-se, então, um questionamento desta teoria e do programa de pesquisas de Cuvier, que objetivava atingir um sistema de classificação natural baseado na organização corporal e não em genealogias como passaram a basear-se os sistemas de classificação taxonômicos após a aceitação da Teoria da Unidade de Tipo de Darwin, momento em que um novo paradigma se instalou na Paleontologia.
\end{abstract}

